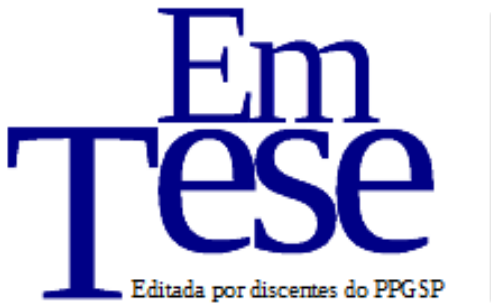

UFSC

PPG SP PROG RAMA DE

V. 15, n. 2 p. 01, Julho, 2018.

DOI: http://dx.doi.org/10.5007/1806-5023.2018v15n2p177

\title{
A Racionalidade de Max Weber e a fabricalização das instituições de ensino superior privadas ${ }^{1}$
}

\author{
Edson Paiva Soares Neto ${ }^{2}$ \\ Andréa Bittencourt Pires Chaves ${ }^{3}$
}

\begin{abstract}
Resumo: A presente discussão apreciará como a sociologia clássica, sob a voz de Max Weber (18641920) pode suscitar a investigação científica crítica a respeito da natureza do Capitalismo e das organizações empresariais no século XXI. Para o estudo, realizou-se pesquisa de campo em BelémPará, com uso de entrevistas e observação das práticas docentes; o Método Compreensivo e o recurso heurístico denominado de tipo ideal para analisar a denominada fabricalização das Instituições de Ensino Superior Privadas no âmbito brasileiro, como expressão fenomênica modelada pelo paradigma burocrático e o acirramento do empresariamento da educação superior brasileira (gestão com fins econômicos e lucrativos) que se propõe a traduzir: o agudo processo de racionalidade técnica e científica, sob a lógica da valorização dos ganhos de capital e os seus impactos nas formas de dominação e controle na gestão dos trabalhadores docentes.
\end{abstract}

Palavras-chave: Max Weber. Racionalidade. Burocracia. Instituição de Ensino Superior. Trabalho docente

\section{The Rationality of Max Weber and the manufacturing of private higher education institutions}

\begin{abstract}
The present discussion will appreciate how the classical sociology, under a voice of Max Weber (1864-1920), can elicit scientific research on the nature of capitalism and business organizations in the twenty-first century. For the study, field research was conducted in Belém-Pará, using interviews and observation of teaching practices;The Comprehensive Method and heuristic resource called ideal type to analyze the so-called manufacturing of Private Higher Education Institutions in the Brazilian context, as a phenomenal expression modeled by bureaucratic paradigm and the intensification of the Brazilian higher education business (management with economic and profitable Finance), which aims to translate: the acute process of technical and scientific rationality, under the logic of the valorisation of capital gains and their impacts on the forms of domination and control in the management of teaching workers.
\end{abstract}

Keywords: Max Weber. Rationality. Bureaucracy. Institution of Higher Education. Teaching work

\footnotetext{
1 (c) EY Esta obra está licenciada com uma Licença Creative Commons Atribuição 4.0 Internacional.

${ }^{2}$ Mestre em Ciências Sociais, Professor da Universidade Federal Rural da Amazônia. Doutorando do Programa de Pós-Graduação em Sociologia e Antropologia da Universidade Federal do Pará. E-mail: ppgcs.edsonpaiva@gmail.com

${ }^{3}$ Doutora em Ciências Sociais, Professora da Faculdade de Ciência Sociais e do Programa de Pós-Graduação em Sociologia e Antropologia, da Universidade Federal do Pará. E-mail: andreachaves@ufpa.br
} 


\section{INTRODUÇÃO}

O presente texto tem como objetivo discutir o pensamento de Max Weber como fonte para a compreensão da natureza do capitalismo e suas aplicações nas organizações empresariais no século XXI, tendo a burocracia como maior expressão fenomênica da racionalidade e das relações de poder nas organizações. Diante disso, propõe-se examinar a categoria fabricalização como aprofundamento do processo de dominação das organizações em relação aos trabalhadores docentes, ainda que tal fenômeno não se restrinja aos docentes.

As influências, contextos e concepções de Max Weber foram apresentados no decorrer da exposição dos tópicos e constam também no trabalho por meio das notas de rodapé, com intuito de estabelecer aproximação analítico-crítico do pensamento weberiano e as possíveis correlações com os fenômenos sociais contemporâneos.

A exposição do tema está estruturada em cinco tópicos: 1. A origem do pensamento de Weber 2. A epistemologia de Max Weber 3. A racionalidade burocrática: sentidos e repercussões 4. A racionalidade burocrática e a "profissionalização administrativa" das Instituições de Ensino Superior brasileiras 5. A racionalidade burocrática e a fabricalização do trabalho docente.

\section{A origem do pensamento de Weber}

Há uma área em que o pensamento de Weber se mostra extremamente fecundo: ele é muito bom para pensar grandes processos históricos, em termos comparativos. Mas é especialmente bom do outro lado que é o de analisar conjunturas, processos dinâmicos que ocorrem localizadamente numa escala menor, porque o esquema dele é muito qualificado para a reconstrução das linhas de forças que se dão e se movem constantemente em situações de conjunturas turbulentas. (COHN, 2003).

Max Weber é um pensador eloquente de uma Alemanha marcada pela diversidade de pensamento, de paradoxos e contradições de várias correntes filosóficas, tais como: o positivismo e suas comparações entre as ciências da natureza e as ciências do espírito; o historicismo alemão baseado na compreensão do fenômeno social com base na recuperação de um sentido, demarcado por uma temporalidade e relativismo; o materialismo histórico marxista e suas observações da história social fundadas nos fatores de ordem material (QUINTANEIRO et al, 2009).

A Alemanha do século XIX caracterizou-se também pela formação tardia enquanto Estado-Nação, por um rápido processo de industrialização, sob a condução de um regime 
militar profissionalizado e pela forte centralização político-administrativa com pretensões expansionistas e, fundamentalmente reticente a respeito das ações necessárias para um protagonismo alemão nas diferentes esferas sociais, econômicas, políticas, tecnológicas e culturais.

Diferentemente da Inglaterra que passara desde o século XVIII pela Revolução Industrial com incrementos tecnológicos, como a mecanização da produção agrícola e industrial, o aprimoramento de novas matrizes energéticas (eletricidade e motores a combustão), assim como na formação de uma burguesia ${ }^{4}$ influente economicamente, politicamente e socialmente, a Alemanha em menor dimensão apresentava uma tímida participação social nas questões políticas (Estado centralizador), fato observado por uma burguesia ascendente e desorganizada e de trabalhadores industriais influenciados pelo ideário socialista. Logo, Weber não reconhecera nem na remanescente formação social feudal, nem na formação sócio-econômica do incipiente capitalismo alemão um programa político capaz de atender a nação na sua mais variada composição social (GIDDENS, 1998).

Outra situação emblemática refere-se à França, no contexto do século XIX que, ao passar por uma reorganização política, social e cultural no século XVIII com a Revolução Francesa assumiu juntamente com a Inglaterra o "status" de representantes do pensamento burguês.

O descompasso no desenvolvimento da nação alemã gerou uma particularidade filosófica: enquanto que Inglaterra e França viviam a dinamicidade do industrialismo e os seus respectivos avanços empíricos, tecnológicos, as descobertas das ciências físicas e biológicas e a tentativa da adaptação de métodos e princípios das ciências naturais para a explicação da realidade social; a Alemanha do século XIX passou a ser influenciada pela valorização da História e da Antropologia. Tal fato é percebido pela ênfase dada ao nacionalismo, à integração e memória nacional, em suma a diversidade no âmbito social, enquanto que França e Inglaterra voltaram-se para a universalidade (COSTA, 2005).

Tal contextualização é relevante tendo em vista que o interesse de Weber em compreender o processo de racionalização da vida moderna no bojo do capitalismo repercutiu na posição política do referido pensador, posicionando-se favoravelmente no que concerne à expansão do capitalismo industrial e da corrente liberal na Alemanha. Ressalva-se, que Weber buscou nas múltiplas ações do sujeito (papel científico, político, religioso, histórico-cultural) compreender o movimento dos sentidos e significados das ações humanas, observando-se a

\footnotetext{
${ }^{4}$ Burguesia é entendida: “como 'gente com posses e cultura': empresários, rentistas, e, em geral todas as personalidades dotadas de formação acadêmica e, com isso, de um certo padrão estamental, de prestígio social. " (WEBER, 2006, p. 62)
} 
pluralidade dos fatores e suas conexões causais. Daí deriva o esforço do referido pensador intelectual discutir epistemologicamente e metodologicamente o agir científico enquanto compreensão do real e a objetividade do conhecimento nas ciências sociais.

Como ponto de partida das correntes filosóficas que influenciaram Weber seja criticando, seja aderindo ao modo de pensamento destacaram-se, respectivamente: a corrente

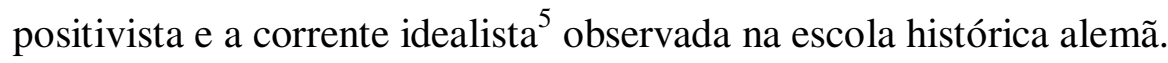

A corrente positivista defendia que a humanidade passava por um processo linear de desenvolvimento e que os estágios dessa evolução ocorriam de modo semelhante em todas as sociedades $^{6}$; já a corrente histórica, incluindo-se Weber, questiona o fato de o positivismo não considerar as peculiaridades históricas para examinar a realidade social, um claro sinal da oposição entre diversidade e universalidade.

Max Weber recusou-se a analisar a sociedade a partir de concepções teleológicas e deterministas, pois segundo LALLEMENT (2008, p. 258): “A característica própria dessa filosofia é encarar a história universal, ou como o desdobramento de uma lógica própria ou como simples resultante de um elemento determinante (economia, religião)".

Para Weber, o entendimento da realidade social não podia se restringir a um determinismo econômico e a subordinação a leis e regras que compõem as dimensões explicativas dos fenômenos sociais (como a crítica que dirige ao pensamento de Karl Marx), visto que para Weber, a realidade é impossível de compreendê-la em sua totalidade.

Weber opôs-se à concepção marxiana que considerava como questão central na compreensão dos fenômenos sociais no âmbito do capitalismo o sistema de classe baseado na relação capital e trabalho assalariado. Para Weber, o aspecto central de diferenciação do capitalismo moderno é a especialização burocrática de tarefas. (GIDDENS, 1998, p. 47). Sendo esta, a maior expressão para Weber do processo de racionalização da vida social.

No pensamento weberiano, o conceito de racionalização abrange três conjuntos de fenômenos relacionados entre si: suas dimensões positiva e negativa (intelectualização e desencantamento, respectivamente); a racionalidade, tendo a calculabilidade precisa como elo prático entre meios e fins e um ethos pautado na razão (GIDDENS, 1998, p. 55).

\footnotetext{
${ }^{5} \mathrm{O}$ idealismo reconhece a relevância da história particular de cada sociedade, da individualidade e da subjetividade para a compreensão da realidade social.

${ }^{6}$ ARON (1999, p. 450) pondera que Weber se identificava com a ciência positiva, racional e com a prerrogativa de descobrir a verdade, pautada em dois aspectos: 1) o não-acabamento essencial, em razão da impossibilidade da elaboração de um sistema completo de leis sociais e a objetividade; 2) validação da ciência por meio do rigor metodológico e rejeição dos juízos de valor no resultado da pesquisa.
} 
Logo, a racionalização da vida social no âmbito do capitalismo ganhou novos contornos, conforme destaca Weber, a partir da conduta racional da vida econômica ${ }^{7}$.

No contexto atual, tais aspectos são também observados, nas instituições governamentais e sua ordem estatal legal, o direito e seu quadro normativo e coercitivo, organizações empresariais de um modo geral, as quais fazem uso de aprimorados e dinâmicos meios de racionalização tecnológica, em destaque as Tecnologias de Informação e Comunicação (TIC) e de gestão administrativa, com a sofisticação dos métodos e técnicas advindos de múltiplas fontes, tais como: empresas de consultoria, instituições de ensino e pela cooptação de trabalhadores por meio da gestão por competências, a qual condiciona a remuneração às metas de produtividade e incita uma postura empreendedorista, resiliente, proativa e comprometida. O próprio indivíduo é provocado pela ideologia individualista e competitiva do capitalismo a pensar a carreira como um jogo racional de estratégias, para que consiga a tão almejada empregabilidade e/ou diferenciação de mercado. Tais aspectos são também observados, por exemplo, em Instituições de Ensino Superior Privadas brasileiras.

Portanto, a racionalização da vida social é fulcral no desenvolvimento do capitalismo, do Estado-Nação e seus aparatos justificadores de dominação (sumo poder legal e sumo poder da força), empresas públicas e privadas, incluindo-se o próprio indivíduo, sendo este um agente que pode ou não influenciar e/ou resignar-se diante do meio. Tal aspecto fomentou em Weber questionamentos e elaborações epistemológicas.

\section{A epistemologia de Max Weber}

A sociologia de Weber opõe-se a abordagens que consideram o indivíduo apenas com mero produto socializado do meio. Ao seguir essa lógica, a sociedade assumiria papel central nos estudos sociológicos, relegando a importância da deliberação subjetiva e voluntária de cada indivíduo. Tal oposição pode ser observada na cuidadosa reflexão epistemológica de Weber sobre a ciência sociológica, a ação social e a delimitação do objeto de pesquisa:

O termo 'sociologia' está aberto a muitas interpretações diferentes. No contexto usado aqui significará aquela ciência que tem como meta a compreensão interpretativa da ação social de maneira a obter uma explicação de suas causas, de seu curso e dos seus efeitos. Por 'ação' se designará toda a conduta humana, cujos efeitos vinculem a esta ação um sentido subjetivo. Tal comportamento pode ser mental ou exterior; poderá consistir de ação ou de omissão no agir. O termo 'ação social' será reservado à ação cuja

\footnotetext{
${ }^{7}$ A gênese do espírito capitalista no meu sentido do termo pode ser pensada como a passagem do romantismo das aventuras econômicas para a conduta racional da vida econômica. (WEBER apud COHN, 2008, p. 24).
} 
intenção fomentada pelos indivíduos envolvidos se refere à conduta de outros, orientando-se de acordo com ela (WEBER, 2002a, p. 11).

Weber ao delimitar o campo de atuação da sociologia posicionou-se contrariamente às escolas organicistas de pensamento ${ }^{8}$, ao criticar o holismo organicista e a integração de seus elementos como uma estrutura definida em um grande "sistema". Nesse sentido, o referido pensador chama a atenção para as possibilidades das referidas correntes de desprezarem ou secundarizarem as relações de conflitos, poder e tensões na conduta social, questões centrais no pensamento weberiano.

Portanto, Weber criticou a mera sujeição do indivíduo ao cumprimento de um quadro valorativo-normativo-institucional da sociedade, omitindo, portanto, a capacidade individual de interpretar subjetivamente o exterior e de realizar ações que podem não representar necessariamente o que a sociedade propugna.

O pensamento weberiano, ao enfatizar a importância do indivíduo na análise da ação social, propõe como fundamento metodológico a compreensão interpretativa ${ }^{9} e$ subjetiva da percepção das pessoas sobre suas ações sociais. De outra forma, as pessoas não são apenas seres sociais, enquadrados em uma classe produtiva, mas também seres capazes de racionalizar, interagir, aceitar ou questionar um conjunto de valores morais ou ideias e de ocupar diversos papeis sociais. $\mathrm{O}$ ato de racionalizar, decidir e a liberalidade individual assume uma condição relativizadora, isto é, o método compreensivo procura reconhecer e destacar a importância das diferentes razões que levam à ação social. Por conseguinte, Weber opõe-se à previsibilidade comportamental do indivíduo, frente ao estímulo exterior, conforme defendem o pensamento positivista e behaviorista, assim como o estruturalismo e as estruturas determinísticas que insinuam a minimização da habilidade e iniciativa individual para atuar e interferir na realidade.

Ao cogitar analisar as diferentes razões para explicação de uma determinada ação social o pensamento weberiano propõe que se observe a realidade considerando diferentes construções possíveis e o porquê de determinada ocorrência ter efetivamente se tornado real. ${ }^{10}$

Diante dessa perspectiva de observação e análise Max Weber utilizou um recurso metodológico denominado tipo ideal como meio de observar traços da ação social em

\footnotetext{
${ }^{8}$ Toma-se, como exemplo, o pensamento romântico e conservador alemão do início do século XIX e pensamento francês de Auguste Comte e Émile Durkheim.

${ }^{9}$ Entender o sentido de um fenômeno não como método explicativo com base na elaboração de leis gerais de causa e efeito, nem a totalidade de um fenômeno, mas a conexões causais de um determinado fenômeno (WEBER, 2002a, p. 18).

${ }^{10}$ Com base no conhecimento disponível, Weber elabora construções e mede: 1) o que então era conscientemente possível para as pessoas cuja ação era decisiva. 2) Em seguida, em confronto com o possível, aquilo que efetivamente aconteceu, para perguntar qual era a causa específica pela qual, de entre os múltiplos possíveis, precisamente esse tenha-se tornado real (JASPERS, 1977, p. 128).
} 
diferentes condições históricas, bem como a dimensão que tal fenômeno pode gerar na sociedade:

Trata-se de recurso metodológico para ensejar a orientação do cientista no interior da inesgotável variedade de fenômenos observáveis na vida social. Consiste em enfatizar determinados traços da realidade - por exemplo, aqueles que permitam caracterizar a conduta do burocrata profissional e a organização em que ele atua - até concebê-los na sua expressão mais pura e consequente, que jamais se apresenta assim nas situações efetivamente observáveis (COHN, 2008, p. 8).

Ao desvendar o fenômeno e a sua ocorrência nos fatos por meio da história, Weber dava início ao processo de desvelamento do evento, não restringindo sua compreensão do fato ao que está posto no "real", mas também ampliando o sentido e as dimensões do evento. ${ }^{11}$

Nesse percurso do cientista social de desvendamento e desvelamento da realidade, Weber ressalvava que pela própria limitação e finitude do espírito humano, o objeto a ser pesquisado se apresenta como um fragmento limitado da compreensão científica, visto que dentre tantos fatos da realidade a serem pesquisados o cientista social identifica e pesquisa um determinado tema e/ou objeto.

Ao escolher o objeto que será pesquisado o pesquisador se depara com um novo dilema: é possível para o investigador social abster-se dos seus próprios valores na análise de uma determinada ação social? A resposta de Weber é que os valores devem ser: “(...) incorporados conscientemente à pesquisa e controlados através de procedimentos rigorosos de análise, caracterizados como 'esquemas de explicação condicional" (QUINTANEIRO et al, 2009, p. 109).

Ao considerar esse último aspecto, Weber argumentou que o agir científico não está destituído de valores, no entanto não se deve confundir tal assertiva a uma abordagem restritiva que defende que o cientista deve estabelecer um distanciamento com o objeto ou a coisificação da pesquisa social. Nesse sentido, o agir científico defendido por Weber baseouse em: neutralidade axiológica, individualismo metodológico, a delimitação das fronteiras da ciência sociológica e do cientista social. Em consequência, ao elaborar os referidos sistemas conceituais, Max Weber foi alvo de polêmicas e críticas ${ }^{12}$.

Ao ponderar a parcialidade na relação entre sujeito e objeto, Weber sustentava que os eventos que se fazem interessantes passam pelo filtro da valoração subjetiva do observador,

\footnotetext{
${ }^{11}$ Ele próprio exprimiu o método que é essencial para isso: é preciso ver os possíveis para captar o real. No presente, o projeto do possível é o espaço no qual eu me asseguro daquilo que decido; sem possibilidade eu não tenho liberdade; sem ver o possível minha ação é cega, somente com o conhecimento do possível eu sei o que realmente eu faço (JASPERS, 1977, p. 127).

12 (...) temos o Weber de Talcott Parsons, quase um 'sociopsicólogo', o Weber positivista de Adorno/Horkheimer, um apologista do status quo, o Weber fenomenológico de Alfred Schutz, e o Weber preso à ilusão objetivista de Lucien Goldman e Michel Löwy, inter alia (LAZARTE, 2001, p. 27).
} 
de outro modo o objeto a ser estudado manifesta-se "dentro e fora de nós, sob uma quase infinita diversidade de eventos que aparecem e desaparecem sucessiva e simultaneamente" (WEBER, 2006b, p. 44).

Da pretensa objetividade e normatividade do agir científico, infere-se o risco do engendramento do dogmatismo na compreensão da realidade e, consequentemente na concepção da verdade. Assim como, numa situação oposta de forte inclinação política e/ou partidária sobre um determinada problemática social.

Souza (2008, p. 43) considera que Weber foi capaz de captar a "ambiguidade constitutiva" do racionalismo singular ocidental: "uma concepção liberal afirmativa e triunfalista; e uma concepção crítica desse mesmo racionalismo que procura mostrar sua unidimensionalidade e superficialidade".

Weber ao reconhecer a inevitabilidade da racionalidade nas diferentes esferas da vida social era ciente de que o domínio da razão técnica, forjada pelo ethos burocrático, poderia repercutir na condução do Estado-Nação por técnicos, desatrelados da função política e do fomento à participação social.

\section{A Racionalidade Burocrática: sentidos e repercussões}

A característica propriamente decisiva da fábrica moderna não está nem nos instrumentos usados, nem no tipo de trabalho, e sim na apropriação da oficina, dos instrumentos, da fonte de energia e da matéria-prima na mão de uma única pessoa, o empresário. (WEBER, 2006, p. 46). Grifo nosso.

Conforme Sennett (2006, p. 29) Weber identificava nas formas da moderna organização social traços de uma fonte tipicamente militar, especialmente no que se refere às estruturas sociais e seus respectivos papéis, desempenhados como um conjunto articulado de funções, tais como peças de engrenagens, precisamente planejados.

Weber foi precursor nos estudos sobre relações de poder nas organizações, nas relações entre os indivíduos, a partir de uma compreensão dos fatos e das elaborações categoriais sobre: autoridade, poder $^{13}$, dominação ${ }^{14}$ e legitimidade, sendo a Burocracia um tipo de poder, organizado sob um sistema racional.

\footnotetext{
${ }^{13}$ Compreende-se como: a oportunidade existente dentro de uma relação social que permite a alguém impor a sua própria vontade mesmo contra a resistência e independentemente da base na qual esta oportunidade se fundamenta (WEBER, 2002a, p. 97).

${ }^{14}$ Entende-se: a oportunidade de ter um comando de um dado conteúdo especifico, obedecido por um grupo de pessoas, (...) deve ser mais preciso e pode significar apenas a probabilidade de que o comando será obedecido (WEBER, 2002a, p. 97).
} 
No decorrer do Século XX, a Burocracia foi examinada empiricamente e criticada, destacando-se os estudos de Robert K. Merton, Philip Selznick e Michel Crozier, nos quais questionaram as disfuncionalidades do modelo burocrático, pela ineficiência administrativa no que se refere às estruturas e normas organizacionais em situações de imprevisibilidade e incertezas do ambiente de negócios. Como exemplo, cita-se a crítica de Crozier (1983) ao sistema universitário francês: o acesso à educação de qualidade, ocupado predominantemente pela elite francesa e a manutenção das castas tradicionais. Tais aspectos foram contestados pelas novas camadas pequeno-burguesas na França de modo veemente no decorrer da década de 1960, as quais criticavam o acesso ao sistema de ensino superior ${ }^{15}$ e a qualidade da educação superior:

A contestação se levantaria naturalmente no seio de grupos que descobriam ser desprezados, a educação superior que constituía sua promoção social reduzindo-se à passagem por uma fábrica cultural que lhes dava apenas conhecimentos disparatados com possibilidades medíocres de carreira (CROZIER, 1983, p. 128-129).

Portanto, sinal presciente do modelo de educação em massa com qualidade relativizada, segmentada por classes de consumo.

Para Sennett (2006, p. 29), as consequências da administração burocrática nas organizações podem ser analisadas sob dois prismas: a organização e os sujeitos constituintes desta. Sendo que a primeira Weber considerava, com sua estrutura piramidal burocrática, uma contribuição para a justiça social, visto que cada posto define o talento e a qualidade de cada indivíduo. Contudo, o próprio Weber via na estrutura burocrática o quanto esta poderia ser prejudicial à liberdade individual.

Ao invés da redenção, por meio do trabalho assalariado o homem burocrático estava limitado em uma "jaula de ferro". Nesse sentido, questiona-se se o propalado discurso meritocrático promove efetivamente a justiça social dos membros da organização, em destaque a promoção social por meio do sistema educacional com viés burocrático.

De acordo com Sennett (2006), a partir da década de 1970, com a chamada reestruturação produtiva do capital, as empresas estabeleceram novos parâmetros produtivos, baseados na adaptabilidade e flexibilidade organizacional. Com isso, a administração burocrática passou a ser revista pelo "excesso de formalidade" e visão "deliberadamente

\footnotetext{
${ }^{15} \mathrm{O}$ sistema universitário e a elite tecnocrática haviam completamente ignorado a chegada dessa enorme massa porque os únicos domínios que lhe eram realmente importantes, as Grandes Escolas, a seleção dos grandes concursos e a manutenção dos privilégios a elas ligados não eram atingidos por essa invasão (CROZIER, 1983, p. 127).
} 
voltada para procedimentos internos, reduzindo com isso a interface com o ambiente externo", conforme os ideólogos do management contemporâneo.

Sob o prisma das organizações empresariais, a "racionalidade" do modelo burocrático não foi capaz de atender aos novos ritmos de "geração de valor"16 e acúmulo de capital, acentuados pela intensificação da competição interempresas e países e na diferenciação competitiva baseada na redução de custos e inovação. Consequentemente, o trabalho especializado e limitado pelo normalismo institucional (gestão autorreferida) foi gradativamente questionando por modelos e técnicas de gestão que apregoam a necessidade de processos mais dinâmicos, adaptáveis a tendências e cenários complexos de competição e consumo, tais como a personalização no consumo de produtos e serviços e a busca de meios racionais que permitam a calculabilidade da produção de bens imateriais, como exemplo a mercadorização da educação, como produto cultural de massa, com aparência customizada.

O segundo aspecto diz respeito ao plano individual, descrita pela despersonalização de relacionamentos sociais, já que o caráter impessoal salienta o cargo e não o indivíduo em si. Ademais, diz respeito a uma pragmática de sujeição ao formalismo e à normalização institucional por parte do empregado, o que provoca limitação quanto ao discernimento de sua atividade dentro de um contexto mais amplo, além da inibição a processos de espontaneidade e criatividade.

Diante desse raciocínio, deduz-se que a formação do sujeito no contexto de uma racionalidade moderna fundada sob um paradigma burocrático tende à reprodução de um indivíduo com trivial capacidade de execução de tarefas ou atividades tecnocráticas. Logo, a formação humanística, o discernimento e encadeamento crítico de questões sociais, políticas, culturais e artísticas diminuem, em contraste a uma formação cultural que valoriza e amplia as dimensões de alcance de terminologias empresariais (tais como melhorar eficiência, controle do tempo, eficácia das ações - ação social com relação aos fins e valores) para diferentes esferas da vida, em suma a exacerbação da racionalidade tecnicista-empresarial

Cabe ressalvar que, apesar da apologia administrativa que defende técnicas de gestão que "valorizam" atributos individuais e componentes subjetivos (criatividade, iniciativa e liderança, por exemplo), a racionalidade técnica, disciplinadora e ordenada sob uma base legal permanece como fundamento da administração contemporânea. Basta citar a legalização e funcionamento jurídico-institucional das empresas e os procedimentos administrativos de comercialização de produtos e/ou serviços; e nas relações de trabalho mediadas sob a tutela

\footnotetext{
${ }^{16} \mathrm{O}$ sentido de valor empregado nesse caso refere-se a uma perspectiva econômica de ganho material ou imaterial (tais como o valor da marca, capacidade de inovação da organização).
} 
jurídica do Estado (a maior expressão do modelo racional-legal). Por conseguinte, a necessidade do controle do trabalho amparado sob uma base legal.

A Administração Burocrática permanece indispensável, sob a lógica do controle das massas. Seu fundamento está no exercício da dominação baseado no saber, que reside no conhecimento técnico e nos métodos econômicos na produção de bens. Logo, as organizações modeladas por fundamentos da administração burocrática podem se tornar ainda mais poderosas, considerando-se dois aspectos dinâmicos e adaptáveis: o domínio do conhecimento técnico e o domínio proveniente da prática administrativa, o "segredo profissional" (WEBER, 1976, p. 27).

Portanto, o empresário hoje ganhou novos contornos:

1) Quanto ao poder econômico: visto que muitas empresas recebem aporte financeiro provenientes de investidores e acionistas interessados na expansão de novos negócios e na expectativa de lucros; administram grandes corporações com atuação global, implementam estruturas produtivas que exigem recursos vultosos, o qual elimina ou restringe a possibilidade de novos entrantes no universo dos negócios;

2) Quanto ao poder técnico e profissional: o empresário hoje carrega consigo o "segredo profissional", derivado de experiências e práticas de negócios em vários mercados; apropriou-se do segredo profissional de outros empresários por meio de aquisições e fusões de empresas do mesmo setor; não restringe o raio de alcance dos mercados a territórios nacionais, mas sim em negócios globais: cultura, gestão, tecnologias, produtos, serviços e informações globais. O empresário hoje é global. Os serviços educacionais estão inseridos nesse fenômeno.

\section{A racionalidade burocrática e a "profissionalização administrativa" das instituições de ensino superior brasileiras}

Há quem questione se nos países signatários do neoliberalismo existem investimentos em políticas sociais. A resposta desvela o contexto que vive a educação superior no Brasil.

Apesar de um pretenso esforço estatal, de 2007 a 2016, da chamada Reestruturação e Expansão das Universidades Federais (REUNI), tal política objetivou reorganizar a carreira dos trabalhadores federais, de modo a ajustá-lo a uma lógica produtivista e precarizada, digase de outro modo que o exercício da função docente em condição exclusiva nos dias atuais se dá pelo sucateamento dos recursos infraestruturais, comprometendo as relações de ensino, pesquisa e extensão; ocorrências de professores realizando atividades técnicas e de gestão sem 
remuneração (funções gratificadas); pesquisas com escassez de apoio financeiro institucional, mas que devem ser implementadas tendo em vista as exigências por produtividade em pesquisa e publicação em periódicos com classificação relevante (parâmetro Qualis).

Portanto, longe de reconhecer na universidade pública gratuita um papel central na formação acadêmica da maioria dos cidadãos: em 2015, das 8.027.297 matrículas de graduação presencial e a distância, 24,3\% das matrículas foram realizadas em Instituições de Ensino Superior Públicas. Quando se observa o número de IES Públicas, o dado revela que a lógica da educação superior é privatizante, isto é apenas 12,48\% (295 instituições), em contraste com as 2069 Instituições de Ensino Superior Privadas (IES Privadas).

A privatização da Educação Superior pode ser melhor compreendida quando são observadas variáveis diversas tais como: os processos sócio-históricos, políticos e econômicos ligados à questão social. Daí se constata que a ofensiva neoliberal não representa um processo superado no Brasil, como cogitado por alguns analistas que defendem que o Brasil viveu uma fase neodesenvolvimentista, mas de aprofundamento de ajustes fiscais, modeladas por teses e recomendações orientadas por interesses nacionais e organismos internacionais como Banco Mundial e Organização Mundial do Comércio, por exemplo. Em consequência, acentua-se a reforma do Estado, sob a lógica da privatização dos serviços sociais educacionais e a mercadorização como resposta à questão social.

Paralelamente ao REUNI, em 2007, deu-se início no Brasil a abertura de capital e participação na Bolsa de Valores de quatro Instituições de Ensino superior privadas: Anhangüera Educacional, Kroton Educacional, Estácio Participações e SEB (Sistema Educacional Brasileiro).

Em 2008, uma onda de fusões e aquisições deu origem a corporações educacionais com aporte de fundos de investimentos. Desde então, o setor educacional privado vem passando por uma "profisssionalização administrativa" baseada em indicadores econômicofinanceiros, na racionalidade de gastos, em busca de "simbiose" e na redução de custos operacionais (PEREZ, 2016). Para isso, tais IES Privadas contam com a participação dos managers $^{17}$, dentre eles os próprios trabalhadores docentes, responsáveis por funções administrativas.

É emblemática a "profissionalização administrativa" que passa as IES incorporadas às corporações educacionais:

\footnotetext{
${ }^{17}$ Classificação realizada pelos autores: Managers, considerados os gestores do capital e do trabalho: que exercem funções administrativas (planejamento, direção, controle e execução) e/ou gestão pedagógica na reprodução da linguagem e competências administrativos junto a docentes e técnicos.
} 
Todos os currículos foram padronizados entre as diferentes unidades e passamos a compartilhar alguns serviços comuns; Deixamos de ser uma empresa que tinha só um canal de distribuição, que era o campus, com só um produto - a graduação - e uma modalidade - a presencial; Quando entramos na bolsa, aplicamos o mesmo conceito para sofisticar a distribuição, o portfólio de cursos, a metodologia e tecnologia, o material didático foi padronizado - José Augusto Teixeira, diretor de Planejamento e Relações com Investidores da Anhangüera Educacional, 2009 (UNIVERSIA, 2009).

Sob esse aspecto, torna-se necessário observar o sentido de técnica para Weber (2012, p. 38 -39), bem como suas possíveis implicações no âmbito das Instituições de Ensino Superior e do trabalho docente:

A "técnica" de uma ação significa a soma dos meios nela empregados, em oposição ao sentido ou fim pelo qual, em última instância se orienta (in concreto); a técnica "racional" significa uma aplicação de meios que consciente e planejadamente, está orientada pela experiência e pela reflexão, e, em seu máximo de racionalidade, pelo pensamento científico. (...) Sempre que se apresentar uma "questão técnica", isso significa que existem dúvidas sobre os meios mais racionais. (...) Em comparação com outros (meios) que talvez ofereçam o mesmo grau de perfeição, segurança e durabilidade do resultado, esses meios têm de ser também os mais econômicos quanto ao esforço que exigem. (...) Do ponto de vista da "gestão econômica", problemas "técnicos" significam o exame dos "custos" (WEBER, 2012, p. 38-39).

Sob o discurso apologético da eficiência empresarial, a chamada "profissionalização administrativa" reconhece e critica as técnicas de gestão, consideradas "amadoras". Dentre as ações administrativas comuns, identificam-se: contratação de executivos, técnicos, comitê de gestão de negócios que aplicarão os conhecimentos especializados do mercado financeiro e da gestão empresarial (marketing, finanças e gestão de pessoas), padronização de processos, sistematização, maior participação, envolvimento e profissionalismo dos professores.

Com relação à gestão do trabalhador docente, a busca de meios racionais, mais econômicos e a revisão de custos, com fins lucrativos é identificada pela perda gradativa do controle e autonomia dos meios de trabalho pelo docente. Sob esse aspecto, Weber (2011, p. 28) já observava esse fenômeno na Alemanha de sua época (1919):

Assim como acontece em outros setores de nossa vida, a universidade alemã se americaniza, sob importantes aspectos. Convenço-me de que essa evolução chegará mesmo a atingir as disciplinas em que o trabalhador é proprietário pessoal de seus meios de trabalho - principalmente de sua biblioteca. Por ora, o trabalhador de minha especialidade continua a ser, tranquilamente, seu próprio patrão, à semelhança do artesão de outrora, no quadro de seu mister próprio. Contudo, velozmente a evolução se processa. (grifo nosso) 
De fato, torna-se relevante compreender as formas de dominação no processo de gestão do trabalho nas IES Privadas, advindas da administração burocrática e de novos discursos e práticas laborativos.

\section{A racionalidade burocrática e a fabricalização do trabalho docente}

Com base na exposição do pensamento de Weber, bem como pesquisa de campo realizada nas IES Privadas na capital paraense ${ }^{18}$, torna-se possível inferir as principais características da burocracia e correlacioná-las com o trabalhador docente, sob a lógica da dominação racional:

Quadro 1 - Características da burocracia e a correlação com o trabalho docente - Magistério superior.

\begin{tabular}{|c|c|}
\hline Características da tipologia da Burocracia & Trabalho docente \\
\hline $\begin{array}{l}1 \text { - Atividades frequentes } \\
\text { objetivos da Organização burtantes aos ática são } \\
\text { distribuídas de forma fixa como deveres } \\
\text { oficiais; rotinas } \\
\text { padronizados) }\end{array}$ & $\begin{array}{l}\text { Divisão do trabalho (Trabalhadores da linha de frente) } \\
\text { - Rotina de Preenchimento de documentos: controle } \\
\text { de frequências acadêmicas, notas, elaboração e } \\
\text { correção de provas, elaboração e revisão de Planos de } \\
\text { Ensino, elaboração de aulas conforme critérios } \\
\text { estabelecidos pela IES }\end{array}$ \\
\hline $\begin{array}{l}2 \text { - A Autoridade }{ }^{19} \mathrm{de} \text { dar as ordens ao } \\
\text { cumprimento dos objetivos é distribuído de } \\
\text { forma estável }\end{array}$ & $\begin{array}{l}\text { O ingresso no grupo de docentes pressupõe a livre } \\
\text { seleção e critérios diversos para a sua permanência }\end{array}$ \\
\hline $\begin{array}{l}\text { - Medidas metódicas são tomadas para a } \\
\text { "realização regular e contínua desses deveres e } \\
\text { para a execução dos direitos correspondentes; } \\
\text { somente as pessoas que têm qualificações } \\
\text { previstas por um regulamento geral são } \\
\text { empregadas". (completa previsibilidade do } \\
\text { funcionamento) }\end{array}$ & $\begin{array}{l}\text { Competência técnica: titulação (especialista, mestre e } \\
\text { doutor), experiência profissional. O trabalho docente } \\
\text { segue as prescrições advindas da IES. }\end{array}$ \\
\hline $\begin{array}{l}4 \text { - A administração de um cargo moderno se } \\
\text { baseia em "arquivos" baseados em rascunhos } \\
\text { ou sua forma original; (Procedimentos } \\
\text { padronizados) }\end{array}$ & $\begin{array}{l}\text { Visão prescritiva e normativa relacionada ao conjunto } \\
\text { de tarefas formais: reuniões, relatórios e atas }\end{array}$ \\
\hline $\begin{array}{l}5 \text { - “Os princípios da hierarquia dos postos e } \\
\text { dos níveis de autoridades significam um } \\
\text { sistema firmemente ordenado de mando e } \\
\text { subordinação, no qual há uma supervisão dos } \\
\text { postos inferiores pelos superiores”; (hierarquia } \\
\text { de Autoridade) }\end{array}$ & $\begin{array}{l}\text { Clara divisão de poder, pouca participação do docente } \\
\text { nos processos de tomada de decisão e no controle da } \\
\text { organização a qual trabalham. O Trabalhador docente } \\
\text { remete-se / subordina-se diretamente à Coordenação } \\
\text { acadêmica e indiretamente a direção institucional }\end{array}$ \\
\hline $\begin{array}{l}\text { 6 -“A administração burocrática, pelo menos } \\
\text { toda a administração especializada - que é } \\
\text { caracteristicamente moderna - pressupõe } \\
\text { habitualmente um treinamento especializado e } \\
\text { completo". (Profissionalização r dos } \\
\text { Participantes) }\end{array}$ & $\begin{array}{l}\text { Treinamentos frequentes sobre procedimentos } \\
\text { pedagógicos, administrativos e legais (portarias, } \\
\text { decretos, deliberações governamentais e da própria } \\
\text { IES Privada - qualificações técnicas incrementadas } \\
\text { para a prestação do serviço }\end{array}$ \\
\hline
\end{tabular}

${ }^{18}$ Pesquisa de campo realizada no período de 2013 a 2017, com trabalhadores docentes de graduação presencial em 15 IES privadas de Belém do Pará, a citar: 1 (uma) Universidade, 1 (um) Centro Universitário e 13 (treze) Faculdades; a técnica utilizada foi a entrevista do tipo não-diretiva aberta, sendo também colhidas informações, por meio de discurso livre de pessoas fontes e observação do cotidiano docente.

${ }^{19}$ Significa a possibilidade de que um comando ou ordem seja obedecido (WEBER, 2002a, p. 55). 


\begin{tabular}{|c|c|}
\hline $\begin{array}{l}7 \text { - Comunicação e relacionamento impessoais } \\
\text { entre sujeitos da organização burocrática (Sina } \\
\text { ira et studio, sem ódio e sem preconceito) }\end{array}$ & Relação social com contornos funcionais \\
\hline $\begin{array}{l}8 \text { - O cargo moderno é reduzido à assimilação } \\
\text { de regras e procedimento normativos }\end{array}$ & $\begin{array}{l}\text { A "profissionalização" docente passa pela assimilação } \\
\text { de diversas regras institucionais }\end{array}$ \\
\hline 9 - Regime meritocrático & $\begin{array}{l}\text { A permanência e/ou promoção na IES Privada está } \\
\text { condicionada ao cumprimento satisfatório dos } \\
\text { objetivos institucionais. Como exemplo: nível de } \\
\text { satisfação do aluno referente às aulas e professores; a } \\
\text { escala salarial, a responsabilidade do cargo e o status } \\
\text { social; a promoção depende de antiguidade, } \\
\text { merecimento ou ambos }\end{array}$ \\
\hline $\begin{array}{l}\mathbf{1 0} \text { - Está sujeito a uma rigorosa e sistemática } \\
\text { disciplina e controle no desempenho do cargo }\end{array}$ & $\begin{array}{l}\text { Previsibilidade e controle sobre o trabalho docente } \\
\text { com estabelecimento de prazos para encaminhamento } \\
\text { de provas, lançamento de frequência, notas, } \\
\text { envolvimento nos projetos pedagógicos institucionais, } \\
\text { frequência docente, padronização de instrumentos } \\
\text { avaliativos, conforme sistema de avaliação } \\
\text { governamental }\end{array}$ \\
\hline
\end{tabular}

Fonte: Elaborado pelo autor, a partir de Weber (2002b, p. 138-139) e de pesquisa de campo (2013-2017).

É possível afirmar que as atividades administrativas realizadas pelo trabalhador docente se restringem ao cumprimento de tarefas burocráticas?

Quais as limitações da categoria burocracia como fonte de compreensão das concepções e práticas de gestão nas Instituições de Ensino Superior Privadas no Brasil?

Somam-se a essas indagações outros questionamentos que podem nortear novas reflexões sobre a ressignificação do trabalho docente no âmbito das IES Privadas, cujo trabalho não se enquadra em atividades burocráticas:

1) Por que os trabalhadores docentes são incentivados/pressionados a desenvolverem um perfil empreendedor?

A retenção dos alunos, deve ser vista como o encantamento dos clientes; o trabalhador docente assume a incumbência de utilizar o próprio networking (rede de contatos pessoais e profissionais), para fomentar a captação de recursos e de estabelecer parcerias comerciais com instituições públicas e privadas, com intuito de conseguir novas turmas, recursos e apoio às atividades e eventos acadêmicos

2) Por que os trabalhadores docentes são incitados a desenvolverem um perfil gerencialista?

Além da competência técnica, torna-se necessário adquirir uma "visão sistêmica da organização", assumindo funções administrativas multifuncionais; propor soluções pedagógicas pragmáticas e utilitaristas que venham "agregar valor" ao negócio educacional. Diga-se novas ou aprimoradas fontes de ganho de capital; as IES Privadas fazem questão de estimular um espírito competitivo entre os próprios docentes e cursos tomando-se como 
parâmetros, nível de satisfação entre turmas e alunos, criação de novas turmas e alcance de resultados pelos docentes, sob a métrica dos indicadores; Propala-se a "gestão democrática e participativa" para discutir e aprovar temas e decisões sugeridas pela alta cúpula da administração institucional.

3) Quais os limites da iniciativa do trabalhador docente? A proatividade, o voluntarismo, a agregação de valor, a exigência de titulação e de publicação científica, em alguns casos sem a contrapartida do apoio financeiro da instituição, podem ser explicados principalmente pela vocação docente? Mas também pela dominação e resignação do docente para permanecer vinculado às IES Privadas

4) Como o trabalhador docente sofre as consequências do produtivismo?

Dentre as medidas, citam-se: reengenharia e/ou reestruturações como downsizing, padronizações culturais, produtivas e busca de "identidades obrigatórias"; a adoção de procedimentos de qualidade e produtividade no tempo certo sob risco de constar no relatório de produtividade individual.

Nessa ofensiva do capital, o discurso ideológico da meritocracia e de atributos empreendedores passaram a ser considerados como características fundamentais de diferenciação e ascensão profissional, um novo ethos empresarial. De outra maneira, o reconhecimento do trabalhador dentro da organização empresarial é enfaticamente condicionado pela capacidade deste de se adaptar rapidamente às mudanças organizacionais, de contribuir intelectualmente na geração de ideias em benefício do capital (cooptação do trabalhador) e, principalmente pela pró-atividade para se qualificar e socializar novos conhecimentos ao demais membros da empresa (teamwork). Portanto, o discurso das organizações empresariais contemporâneas defende que a empregabilidade tem uma relação direta com competências técnicas e atributos comportamentais.

A nova forma de dominação do trabalhador fundada na valorização das inteligências $e$ dos conhecimentos ${ }^{20}$ dá um novo salto qualitativo na "captura" da subjetividade, pois tem na assimilação de experiências e práticas dos trabalhadores (conhecimento tácito) uma nova estratégia de extração de valor pela organização empresarial, seja por meio de geração de ideias de novos produtos e serviços, seja no melhoramento dos processos produtivos.

Conforme Antunes (2002, p. 104-105) destacam-se, no contexto contemporâneo, novas práticas empregatícias no proletariado fabril e de serviços engendradas por processos

\footnotetext{
${ }^{20}$ Nessa nova ofensiva do capital que valoriza os conhecimentos explícitos e tácitos como formas renovadas de geração de valor (geradas principalmente pela força de trabalho), surgem clichês que procuram naturalizar esse processo de extração de valor pelo capital, tais como a "Era do Conhecimento"; a "Era da Informação"; "Sociedade do Conhecimento".
} 
precarizados de contratação da força de trabalho (terceirização, subcontratação, part-time por exemplo). Seria o trabalho docente uma forma de trabalho por si só precarizada, em razão de horas efetivamente não-pagas para a realização das atividades laborativas extraclasse?

Neste cenário de fragilidades nas relações de trabalho (instabilidade e acirrada competição pela manutenção do emprego; contratos de trabalho com menos benefícios sociais) ressalta-se a configuração, desde os anos 1990, de um Estado neoliberal, que defende a redução de direitos e garantias trabalhistas, cuja justificativa para o entrave no crescimento econômico deve necessariamente passar pela reforma (precarização) dos direitos trabalhistas

O que se percebe é que a defesa de um discurso empreendedorista por parte do Estado procurou encobrir o processo de privatização de bens e serviços produzidos pelo Estado neoliberal $^{21}$, bem como na precarização da qualidade na oferta de educação superior a uma camada populacional excluída economicamente, que enxerga na formação superior a possibilidade de ocupar melhor posição no seio social.

Pensar e discutir criticamente a categoria fabricalização não pressupõe a negação de Weber e seus problemas centrais de pesquisa sobre o capitalismo: o fenômeno da racionalização e da burocracia como forma de poder e dominação na vida social. Mas sim, reafirmar sua importância, sem deixar de realizar a crítica necessária para provocar novas reflexões sobre os fenômenos sociais que se apresentam fora do contexto histórico e social do referido pensador alemão.

Diante da exposição e reflexão conceitual em torno da racionalidade e da burocracia, torna-se possível depreender as seguintes particularidades do sentido de fabricalização:

Fabricalização: a premissa de valor é explicita e autorreconhecida, opondo-se à neutralidade axiológica sem pressupostos valorativos. Reflete, assim como o tipo burocrático o desencantamento do mundo, pela crítica à racionalidade que aumenta a alienação, diferentemente de uma concepção libertária em torno do acesso à educação e do trabalho como educador. Tal categoria assume uma posição histórica, pois reconhece nas experiências fabris do capitalismo fontes técnicas e científicas estratégicas para o avanço do capital no processo de dominação (técnicas de qualificação gerencial e empreendedoras do trabalhador docente) e fetichização da materialidade do trabalho humano no campo da produção de conhecimento e suas representações (cultural, histórica, social, política e profissional) resumidas à coisificação do trabalho, a mercadoria-conhecimento é fragmentada e inócua a

\footnotetext{
${ }^{21}$ No plano diretor da reforma neoliberal do aparelho do Estado, de 1995 o Estado, no que tange à educação superior adotou e mantém como estratégia o estímulo ao empresariamento da educação.
} 
consciência de si mesmo enquanto sujeito pensante e constituinte de uma classe, ainda que se considere sua pluralidade e particularidades.

A lógica da mercadoria-conhecimento segue o seguinte roteiro comum na divisão de trabalho fabril: simplificar, tecnificar, reproduzir. Limita-se o conhecimento científico a conteúdos fragmentados e esquemáticos; retira-se conteúdos que demarquem suas relações históricas e conflitivas, concentra-se na aplicação das técnicas "foco na execução" (como processualidade do ambiente administrativo), "foco no cliente" (como processualidade das relações de comercialização e consumo), e reproduz-se às massas (acadêmicas).

\section{Considerações finais}

O pensamento de Max Weber enseja um processo de observação da ação social que apreende e compreende a realidade não somente como ela se apresenta, mas também pela possibilidade do estudo dos fenômenos de forma ampliada e/ou até mesmo superdimensionada (tipo ideal).

Engana-se que a elaboração epistemológica de Weber por meio de tipologias traga descrédito como método de observação social. Pensar a realidade ampliando suas dimensões, conforme ensina Weber tem como propósito chamar a atenção para determinado aspecto da vida social "encoberto" dentre vários fenômenos. Ao destacar determinada categoria torna-se possível estudar suas interrelações, seus impactos e consequências. Toma-se como exemplo a tipologia da Burocracia.

Logo, pode-se considerar que Weber ao elaborar uma tipologia da burocracia, não a apresentou como um ideólogo de um novo paradigma de gestão organizacional, mas sim um observador crítico de suas causas, o ritmo e a intensidade das mudanças nas organizações e nas demais esferas da vida social provocadas pelo fenômeno da racionalidade.

Não se deve desconsiderar a produção de Weber como demarcação crítica frente ao movimento de racionalização da vida moderna e que ainda é capaz de apontar caminhos para a observação dos fenômenos atuais. Diga-se o fenômeno da profissionalização escolar como constructo baseado em indicadores de performance paras os alunos desde a tenra idade ao ensino superior; ou então a expansão das formas de dominação sobre os trabalhadores docentes que vendem suas energias físicas e intelectuais sob a lógica de uma educação de massa com baixa qualidade educacional (salas de aulas lotadas, disciplinas condensadas em web-aulas cuja função docente nos pólos replicadores se restringe ao papel de tutor que ajudará os alunos a responder eventuais dúvidas). 
Weber indubitavelmente não é capaz de responder a todas as querelas sociais emergentes no século XXI. No entanto, a busca pela compreensão dessa realidade seria significativamente prejudicada se não considerasse a busca pela precisão categorial e da observação de Weber sobre o capitalismo e os seus traços fundamentais, em destaque a dominação racional modelada pela administração burocrática

O pensamento weberiano nos faz refletir sobre o espírito humano finito incapaz de compreender a totalidade do conhecimento e da verdade. Tal fato pode ser observado no cuidadoso processo de elaboração e conceituação de categorias básicas da sociologia. Para alguns críticos, o esforço empreendido pelo nominalismo das categorias visa validar o conhecimento científico como uma construção hermética dos fenômenos concretos. Portanto, a compreensão da realidade passa por um rigorosa formulação e análise de categorias, assim como por uma clara distinção entre o registro dos fatos e avaliações valorativas (neutralidade axiológica). Seguramente, não se pode afirmar que se presencia nas organizações uma fase pós-burocrática, pelo contrário, a burocracia se metamorfoseou em um complexo sistema de dominação racional das massas, a qual assumiu um papel nuclear no dinâmico processo de controle e justificação do poder pelas organizações, não se restringindo apenas ao controle formal dos grandes grupos de funcionários, mas também nos pequenos grupos informais gerenciáveis a partir dos avanços dos instrumentos tecnológicos e métodos de gestão econômicas e de recursos humanos, provenientes de um sistema de fabricalização.

Chega-se à conclusão de que a educação superior privatizada e fabricalizada incorpora um viés funcionalista ao sistema capitalista: reprodução de força de trabalho, e uma formação curricular que se volta para melhorias e geração de valor à própria lógica de maiores ganhos. Caminhamos para uma educação superior com profissionais que vão conhecer na Instituição na qual está matriculado a qualidade como acepção de gestão com viés economicistafuncionalista e que não apreciarão uma educação com qualidade crítica e questionadora que pensa além da simples reprodução da força de trabalho. O domínio do lucro alcançou novos níveis. 


\section{Referências}

ANTUNES, Ricardo. Os sentidos do Trabalho: Ensaio sobre a afirmação e a negação do trabalho. $6^{\text {a }}$ ed. São Paulo. Ed. Boitempo, 2002.

ARON, Raymond. As etapas do pensamento sociológico. $5^{\text {a }}$ ed. São Paulo. Ed. Martins Fontes, 1999.

A SOCIOLOGIA de Weber. Palestra de Gabriel Cohn. Produção de Logo on Editora Multimídia. São Paulo: CPFL Cultura, 2003. 1 DVD (50 min.), son. color.

COHN, Gabriel. (org.). Weber. São Paulo. Ed. Ática, 2008

COSTA, Maria. Sociologia: introdução à ciência da sociedade. $3^{\text {a }}$ ed. São Paulo. Ed. Moderna, 2005.

CROZIER, Michel. A sociedade bloqueada. São Paulo. Editora Universidade de Brasília, 1983 ,

GIDDENS, Anthony. Política, Sociologia e Teoria social: encontros com o pensamento social clássico e contemporâneo. São Paulo. Fundação da Editora da UNESP, 1998.

JASPERS, Karl. Método e visão do mundo em Weber. In: COHN, Gabriel. Sociologia: para ler os clássicos. Rio de Janeiro. Livros técnicos e científicos, 1977.

LALLEMENT, Michel. História das ideias sociológicas: das origens a Max Weber. $4^{\mathrm{a}}$ ed. Petrópolis. Ed. Vozes, 2008.

LAZARTE, Rolando. Max Weber: ciência e valores. São Paulo. Ed. Cortez, 2001.

PEREZ, Fabíola. Gigantes da educação. Revista Isto É. São Paulo, [21.01.2016]. Edição 2481. Caderno \& Negócios. Disponível em: $<$ https://istoe.com.br/294090_GIGANTES+DA+EDUCACAO/>. Acesso em 05 ago. 2016.

QUINTANEIRO, Tania et al. Um Toque de Clássicos. 2. ed. rev. e amp. Belo Horizonte: Ed. UFMG, 2009.

SENNETT, Richard. A Cultura no Novo Capitalismo. Rio de Janeiro, Ed. Record, 2006.

SOUZA, Jessé. A Atualidade de Max Weber no Brasil. Revista CULT, n ${ }^{\circ}$ 124, ano 11, p. 42-46, 2008

UNIVERSIA. IES privadas abrem capital para ampliar alcance - Primeiras quatro IES a lançar ações captaram $\mathrm{R} \$ 1,7$ bi com papeis. [23/11/2009]. Disponível em: $<$ http://www.ufcg.edu.br/prt_ufcg/assessoria_imprensa/mostra_noticia.php?codigo=962>. Acesso em 28 ago. 2016.

. A gênese do capitalismo moderno. São Paulo: Ed. Ática, 2006.

$2006 b$.

. A “objetividade” do conhecimento nas ciências sociais. São Paulo: Ed. Ática, 
Conceitos básicos de Sociologia. São Paulo: Ed. Centauros, 2002a.

Economia e Sociedade: fundamentos da sociologia compreensiva. $4^{\mathrm{a}}$ ed. Brasília: Editora Universidade de Brasília, 2012.

Ensaios de Sociologia. $5^{a}$ ed. Rio de Janeiro: Ed. Livros Técnicos e CientíficosLTC, 2002b.

Os fundamentos da organização burocrática: uma construção do tipo ideal. (in) Sociologia da Burocracia. Org., introd. e trad. Edmundo Campos. Rio de Janeiro: Ed. Zahar, 1976.

Recebido em 31-07-2017;

Revisado em 20-08-2018;

Publicação em 15-12-2018. 